\title{
Studies on the Structure of Thin Metallic Films by Means of the Electron Microscope
}

\author{
Robert G. Picard* and O. S. Duffendack \\ Harrison M. Randall Laboratory of Physics, University of Michigan, Ann Arbor, Michigan
}

(Received March 17, 1943)

\begin{abstract}
$\Lambda$ study was made of thin films of aluminum, cadmium, copper, gold, magnesium, and zinc using an RCA electron microscope capable of $30 \mathrm{~A}$ resolving power. The films were formed by evaporation and condensation on collodion substrates in vacuum. An evaporating chamber was devised that permitted control of the temperature of the condensing surface. Photographs of the surfaces show that all the films are made of agglomerates of the metals separated by interstices of various widths. All evidence leads to the con-
\end{abstract}

clusion that the surface structure is explainable by assuming migration of the atoms over the surface. The observed structure can be used to explain the electrical conductivity, the optical reflectivity, and adsorptivity of thin films. Electron microscopic studies also provide a ready means of classifying surfaces according to the mobility of the atoms comprising them, and thus enable a rough estimate of the potential distribution over the surface to be made.

\section{INTRODUCTION}

M ANY investigators have studied the properties of thin films, both metallic and nonmetallic. Special attention has been given to the optical properties, heat and electrical conductivities, oxidation, and catalytic effects of the surfaces. Electron diffraction studies of such films have indicated that they possess some crystalline properties. All lines of investigation have led to the belief that the films are not continuous, but consist of particles with spaces between them.

Recently a new instrument has been made available to the research worker and offers a new approach to the study of thin films. The electron microscope, because of its high resolving power and, hence, large useful magnification, permits direct observation of the structure of thin films to be made. With this added information it should be possible to explain some of the properties and peculiarities of such surfaces.

All of the films studied were formed by evaporation and condensation in vacuum. It was the purpose of this investigation to determine

(1) the suitability of the electron microscope for the study of thin films,

(2) the size of and interstitial distance between the particles constituting the films,

(3) the change in surface structure with film thickness, and

(4) the effect of the temperature of the condensing surface on the film structure.

\footnotetext{
* Now with the U. S. Rubber Company, Passaic, New Jersey.
}

Appleyard ${ }^{1}$ in his studies with Lovell on the conductivity of thin metallic films on Pyrex glass arrived at a picture of the surface in agreement with most of the accepted speculations of previous investigators. $\mathrm{A}^{\circ}$ very thin surface (up to $100 \mathrm{~A}$ in thickness) was considered as being made up of small agglomerates of the metal with spaces between them. Even if a continuous surface were formed by an initial layer of molecules, any imperfection in this surface due to the condition of the substrate might cause cracking. Surface tension forces would then cause the material to take the form of droplets. These forces exert very great pressures on drops a few angstrom units in diameter (the pressure is inversely proportional to the radius of the drop); thus, if the layer were broken it would go over into the stable form of small agglomerates.

Still another factor influencing the structure of thin films is the difference in thermal coefficients of expansion of the metal and the substrate. This can lead to breaking up of the metallic film if it undergoes any appreciable temperature change, and the surface tension forces will favor the formation of agglomerates.

Probably the most important factor in determining the type of surface formed is the ability of the metal atoms to migrate over the condensing surface. The theory of migration of atoms which was developed by Lennard-Jones ${ }^{2}$ satisfactorily explains the experimental results and will be

1 E. T. S. Appleyard, Proc. Phys. Soc. 49, Extra Part, pp. 118-135 (1937)

${ }^{2} \mathrm{~J}$. E. Lennard-Jones, Trans. Faraday Soc. 28, 333-359 (1932). 
discussed with the conclusions from this investigation.

\section{EXPERIMENTAL PROCEDURE}

The electron microscope used in this research was an RCA type $B$ instrument. Its magnification range was from 1200 to 23,000 diameters for the $60 \mathrm{kv}$ accelerating voltage used. A resolving power of about $30 \mathrm{~A}$ was attained.

All observations were recorded photographically on Eastman medium lantern slide plates. The emulsion has a resolving power of 70 lines $/ \mathrm{mm}$. Development with Kodak formula DK-60a and fixing with Kodak F-5 fixing bath gave very satisfactory results. Emulsions with higher resolving power up to $500 \mathrm{lines} / \mathrm{mm}$ are available, but as they are much slower the exposures required would be correspondingly longer, and fluctuations in the instrument during the lengthened exposure time might ${ }^{*}$ well nullify any gain in resolving power obtained from the emulsion. Furthermore, it will be shown that extremely high resolution plates are unnecessary.

In choosing the magnification at which photographs of the specimen were to be made, it was necessary to consider the useful magnification of the microscope. By "useful magnification" is meant that magnification which will reveal all of the detail of the specimen down to the resolving power of the instrument. Any further enlargement is merely for convenience in viewing. The useful magnification is determined by the resolving power of the microscope and the resolving power of the recording medium, either the eye or a photographic plate.

As all studies with the microscope are recorded photographically the useful magnification is limited by the resolving power of the emulsion. Eastman medium lantern slide plates have a resolution of 70 lines $/ \mathrm{mm}$. If the microscope has a resolving power of $30 \mathrm{~A}$, a magnification of 4760 diameters will record this detail on the plate. Less magnification would place points separated by $30 \mathrm{~A}$ in the specimen too close together on the plate to be recorded as separate. Higher magnification would increase the separation on the photographic plate of the images of two points $30 \mathrm{~A}$ apart in the specimen, but could reveal no further detail as the resolving power of the microscope would then become the limiting factor.
A photograph made at a magnification of 4760 diameters thus contains all the possible detail obtainable. However, as the resolving power of the eye is $0.1 \mathrm{~mm}$, this detail cannot be observed visually; so further enlargement of at least 7 times is necessary to enable the eye to appreciate all the detail in the photographic plate. Thus for the eye just to be able to see the entire observable structure of a specimen with a microscope having $30 \mathrm{~A}$ resolution and using a photographic plate capable of resolving 70 lines $/ \mathrm{mm}$, an over-all magnification of at least 33,320 diameters is necessary. This is a minimum estimate as the resolving power of the eye is frequently much poorer than $0.1 \mathrm{~mm}$. Many pictures will stand total enlargements as great as 150,000 diameters without serious loss of definition.

As the microscope itself is capable of magnifications from 1200 to 23,000 diameters, the useful magnification for photographic purposes falls well within its range. Considerable latitude in procedure is available for obtaining high total magnification for naked eye viewing. Pictures may be made with the microscope at $23,000 \mathrm{di}-$ ameters and slightly enlarged optically to a convenient size for study, or they may be made as low as 5000 diameters and enlarged 10 or 15 times. Experience has shown that the latter procedure is not too satisfactory; because, in order to get a photograph capable of such enlargement, extreme care must be taken in the development and fixing of the plate to avoid excessive clumping of the silver grains and hence loss of resolution. The former procedure is also subject to objections, chiefly because the intensity in the final image is so low that accurate focusing is difficult and the exposure time becomes so long that the electrical stability of the instrument cannot be relied upon to give the ultimate resolving power.

It has been found most satisfactory to photograph at a microscope magnification of about 9000 diameters for general work, and if extremely high resolution is needed because of the detailed structure of the specimen (particularly for thin metallic films) a series of photographs made at about 17,000 diameters will give excellent results. Sharp enlargements with over-all magnification ranging from 50,000 to 150,000 diameters can regularly be made from these plates without using special fine grain development technique. 
The apparatus used in evaporating metals consisted of a Cenco "Hyvac" pump acting as fore pump for a mercury diffusion pump. This in turn acted as fore pump for another high speed mercury diffusion pump with liquid air trap from which led an open tube ending in a ground joint. The evaporating chamber had its end ground to fit this tube, and the joint was made vacuum tight by sealing with Picein. This rather complicated vacuum system was used to allow gases released by the metal as it was heated to be pumped off, since the metals could not be conveniently outgassed in any other manner. A McLeod gauge was used to read pressures in the apparatus.

The evaporating chamber (Fig. 1) had two filaments, $F$, connected to the bulb through ground joints and sealed with Picein, thus permitting easy replacement. The filaments were about $3.5 \mathrm{~mm}$ in diameter and 4 to $5 \mathrm{~mm}$ long (10 turns of wire), and the metal to be evaporated was mounted inside one of them. A piece of glass tubing about $14 \mathrm{~mm}$ in diameter was sealed into the bulb as shown so that it could be filled with liquid air or some other substance to control its temperature. The top of the horizontal portion was ground to form a flat surface about $35 \mathrm{~mm}$ long. On this platform, $P$, were placed collodion covered microscope specimen screens (200 mesh) which served as the condensing surfaces. The platform had a slight downward tilt so that no air bubbles would be trapped against it when the tube was filled, thus assuring that it would quickly reach the temperature of the liquid in the tube. As the two filaments were at different distances from the platform, the angle of evaporation as viewed from the specimen could be changed by using one filament or the other.

When an evaporation was to be performed, the metal was first cleaned with distilled water and alcohol and then weighed. The amount to be used was determined by the thickness of specimen desired and which filament was used. In no case did the weight cxceed a few milligrams. The metal was then placed inside the filament and up to four collodion covered wire meshes were placed on the platform. By using several specimen screens in the apparatus at once, it was possible to secure a large variation in thickness of surface deposited. The evaporating chamber was then sealed onto

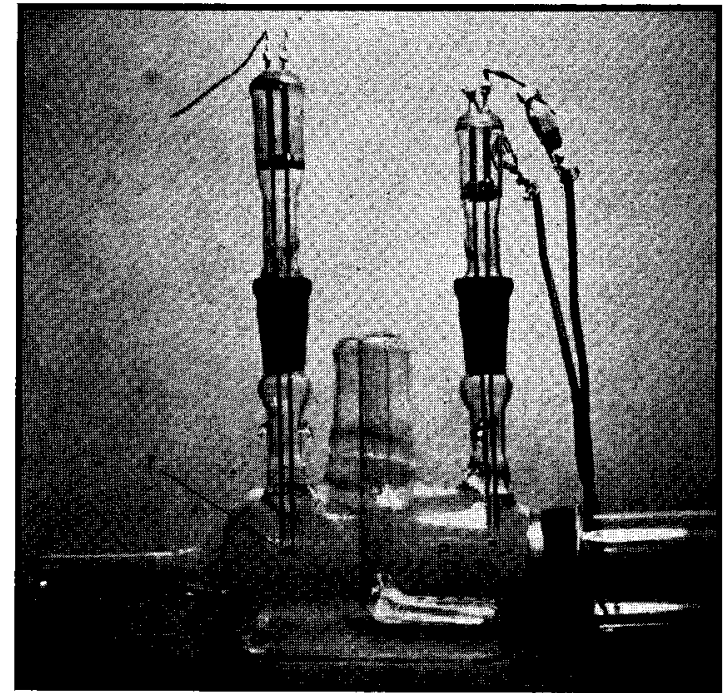

Fig. 1. Evaporating chamber. $F$, filament; $P$, platform tube; $S$, specimen screens.

the pumping system with Picein and evacuated. A sticking vacuum with the McLeod gauge was usually obtained within twenty minutes after the diffusion pump heaters were turned on.

After a high vacuum was obtained the filaments were heated, slowly at first to outgas them and the metal, and then more rapidly until the metal fused or evaporation started. As the filament started to heat, the pressure rose to about $10^{-4} \mathrm{~mm}$ of $\mathrm{Hg}$, but the sticking vacuum was quickly recovered. The metal was not flashed, but was evaporated at a moderate rate over a period of three to four minutes. Finally, the filament temperature was raised to a higher value than that at which good evaporation of the metal occurred in order to clean the filament thoroughly.

When it was desired to have the specimen screens well below room temperature during the evaporation and condensation, the platform tube was filled with liquid air. This was not done, however, until a pressure of less than $10^{-4} \mathrm{~mm}$ of $\mathrm{Hg}$ had been established in the system, and the liquid-air trap on the diffusion pumps had been filled. In this way the possibility of water vapor or mercury vapor condensing on the cooled surfaces was eliminated. The specimen screens were carefully flattened so as to assure good contact between the cold platform and the wire mesh. The evaporation was not started until the rate of 
boiling of the liquid air showed that the glass tube had reached a very low temperature.

The choice of filament from which to evaporate a given metal was made in accordance with the studies of Caldwell. ${ }^{3}$ The metals evaporated and the corresponding filaments used are listed in Table I.

It must be emphasized that the collodion supporting film could not be outgassed due to its fragility and its inability to withstand sufficiently high temperatures, so that gaseous contamination of the substrate was a possibility for all specimens. Furthermore, the specimens had to be removed from the evaporating chamber and then placed in the microscope. As only one film could be studied at a time, the rest were exposed to the atmosphere for periods of a few hours to several days before they could be photographed, and thus some chemical reactions with the air might have taken place.

\section{OBSERVATIONS AND RESULTS}

In this investigation of the nature of metallic surfaces formed by evaporation and condensation in vacuum the first metal studied was aluminum. The surface appearance agreed with that of antimony which was studied by Marton. ${ }^{4}$ The next metal used was zinc in order to see if the electron microscope could throw any light on the reasons why this metal forms poor surfaces on many substrates when condensed from the vapor. The surfaces were quite different from the aluminum, so cadmium was then studied, as its properties were known to be much like those of zinc. Good agreement was found between the two metals. Magnesium was studied because it has the crystal structure of zinc and cadmium (hexagonal). Copper, which has a face-centered cubic lattice as does aluminum, was used for comparison with that metal. Finally, gold surfaces were investigated, as this metal also has the aluminum crystal structure, but does not oxidize on exposure to air; hence, it served as a check on the effects of exposure of the surfaces to the atmosphere. All the metals used were of exceptional purity.

${ }^{3}$ W. Caldwell, J. App. Phys. 12, 779-781 (1941).

${ }^{4}$ L. Marton, J. App. Phys. 12, 763 (1941).
TABLE I. Filaments used in evaporation.

\begin{tabular}{lll}
\hline \multicolumn{1}{c}{ Metal } & Filament & \multicolumn{1}{c}{ Wire size } \\
\hline Aluminum & Tungsten & $0.015^{\prime \prime}$ \\
Cadmium & Chromel & 0.015 \\
Copper & Molybdenum & 0.008 (doubled) \\
Gold & Tungsten & 0.015 \\
Magnesium & Tungsten & $\mathbf{0 . 0 1 5}$ \\
Zinc & Tungsten & 0.015 \\
\hline
\end{tabular}

In all cases during the evaporations the McLeod gauge showed a sticking vacuum, so the pressure was assumed to be $10^{-6} \mathrm{~mm}$ of $\mathrm{Hg}$ or less.

For each run usually four specimen screens were placed in the evaporating chamber at different distances from the filament, thus enabling four surfaces of different thickness to be produced at one time. Some of these screens were found to have no collodion film after the evaporation or were damaged in handling.

The only attempt at controlling the temperature of the condensing surface was made by filling the platform tube with liquid air for several runs. The condensing surface temperatures are stated in Table II as room temperature or liquid air. In the first case no cooling of the specimens was attempted and the temperature of the screens was somewhat above room temperature due to the heat given off by the filament, but the collodion films were never damaged by the heat. When liquid air was used for cooling, the glass was at $-183^{\circ} \mathrm{C}$ and the wire mesh in contact with it must also have been at the same temperature. As the wires occupy about $\frac{1}{2}$ of the total area of the screen, it was assumed that the small areas of collodion between the wires would also come to a temperature in that neighborhood. However, again the heat from the filament raised the temperature of the collodion, but it is safe to assume that the surface temperature remained at least $100^{\circ} \mathrm{C}$ below room temperature.

In Table II are listed pertinent data for all runs. These data were taken to determine the change in the surface structure with the amount of material deposited and the effect of the temperature of the condensing surface on the nature of the metallic film. Unfortunately, the specimens when condensed on a cold surface had to be removed from the evaporating chamber in order to be examined with the microscope, and this necessitated 
TABLE II. List of materials studied and conditions existing during the evaporation. The Roman numerals refer to the number of the evaporation.

\begin{tabular}{|c|c|c|c|c|}
\hline Specimen & Mass (mg) & $\begin{array}{l}\text { Condensing } \\
\text { sirface } \\
\text { temperature }\end{array}$ & $\begin{array}{c}\text { Screen } \\
\text { number }\end{array}$ & $\begin{array}{l}\text { Distance } \\
\text { from } \\
\text { filatnent }\end{array}$ \\
\hline Al I & - & Room temp. & $\begin{array}{l}1 \\
2 \\
3 \\
4\end{array}$ & $\begin{array}{l}37 \mathrm{~mm} \\
42 \\
50 \\
57\end{array}$ \\
\hline AI II & - & Room temp. & $\begin{array}{l}1 \\
2 \\
3 \\
4\end{array}$ & $\begin{array}{l}34 \\
38 \\
43 \\
51\end{array}$ \\
\hline AI III & - & Liquid air & $\begin{array}{l}1 \\
3\end{array}$ & $\begin{array}{l}30 \\
37\end{array}$ \\
\hline AIIV & 9.8 & Liquid air & $\begin{array}{l}1 \\
4\end{array}$ & $\begin{array}{l}38 \\
28\end{array}$ \\
\hline $\mathrm{AV}$ & 9.8 & Room temp. & $\begin{array}{r}1 \\
2 \\
3 \\
4\end{array}$ & $\begin{array}{l}38 \\
34 \\
31 \\
28\end{array}$ \\
\hline $\mathrm{NIVI}$ & 8.2 & Liquid air & $\begin{array}{l}1 \\
2 \\
3 \\
4\end{array}$ & $\begin{array}{l}59 \\
67 \\
75 \\
82\end{array}$ \\
\hline $\mathrm{Zn} \mathrm{I}$ & 4.5 & Room temp. & $\begin{array}{l}1 \\
2 \\
3 \\
4\end{array}$ & $\begin{array}{l}42 \\
35 \\
30 \\
27\end{array}$ \\
\hline $\mathrm{Zn} \mathrm{II}$ & 7.0 & Room temp. & $\begin{array}{l}1 \\
2 \\
3 \\
4\end{array}$ & $\begin{array}{l}38 \\
32 \\
30 \\
27\end{array}$ \\
\hline $\mathrm{Zn} \mathrm{III}$ & 5.1 & Liquid air & $\begin{array}{l}1 \\
2 \\
3 \\
4\end{array}$ & $\begin{array}{l}40 \\
35 \\
30 \\
28\end{array}$ \\
\hline Zn IV & 9.5 & Room temp. & $\begin{array}{l}1 \\
2 \\
3 *\end{array}$ & $\begin{array}{l}40 \mathrm{~mm} \\
35 \\
30\end{array}$ \\
\hline $\mathrm{ZnV}$ & $\begin{array}{l}4.0 \\
5.3^{* * *}\end{array}$ & Liquid air & $\begin{array}{l}1 \\
2 \\
3 \\
4\end{array}$ & $\begin{array}{l}39-63^{* *} \\
34-69 * * \\
30-77 * * \\
28-83 * *\end{array}$ \\
\hline $\mathrm{ZnVI}$ & 3.8 & Room temp. & 1 & $33 * * *$ \\
\hline $\mathrm{Zn}$ VII & 9.5 & Room temp. & $\begin{array}{l}1 \\
2\end{array}$ & $\begin{array}{l}50 \\
35\end{array}$ \\
\hline $\mathrm{CuI}$ & 8.4 & Room temp. & $\begin{array}{l}1 \\
2 \\
3\end{array}$ & $\begin{array}{l}39 \\
34 \\
31\end{array}$ \\
\hline $\mathrm{Cu} I I$ & 6.1 & Liquid air & $\begin{array}{l}1 \\
2 \\
3 \\
4\end{array}$ & $\begin{array}{l}40 \\
34 \\
30 \\
28\end{array}$ \\
\hline
\end{tabular}

TABLE II.-Continued.

\begin{tabular}{|c|c|c|c|c|}
\hline Specimen & Mass (mg) & $\begin{array}{l}\text { Conatensing } \\
\text { sirface } \\
\text { temperature }\end{array}$ & $\begin{array}{l}\text { Screen } \\
\text { number }\end{array}$ & $\begin{array}{l}\text { Distance } \\
\text { from } \\
\text { filament }\end{array}$ \\
\hline $\mathrm{Cd} \mathrm{I}$ & 4.7 & Room temp. & $\begin{array}{l}1 \\
2 \\
3 \\
4\end{array}$ & $\begin{array}{l}38 \\
34 \\
30 \\
27\end{array}$ \\
\hline $\mathrm{CdII}$ & 5.0 & Liquid air & $\begin{array}{l}1 \\
3 \\
4\end{array}$ & $\begin{array}{l}39 \\
30 \\
28\end{array}$ \\
\hline $\mathrm{Cd}$ III & 5.8 & Room temp. & $1^{* * * * *}$ & 32 \\
\hline $\mathrm{Cd} I \mathrm{~V}$ & $\begin{array}{l}4.3 \\
8.4^{* * *}\end{array}$ & Room temp. & $\begin{array}{l}2 \\
4\end{array}$ & $\begin{array}{l}35-68^{* *} \\
28-83^{* *}\end{array}$ \\
\hline Au I & 11.0 & Room temp. & $\begin{array}{l}1 \\
3 \\
4\end{array}$ & $\begin{array}{l}40 \\
31 \\
28\end{array}$ \\
\hline Au II & 10.4 & Roon temp. & $\begin{array}{l}1 \\
2\end{array}$ & $\begin{array}{r}70 \\
113\end{array}$ \\
\hline $\mathrm{MgI}$ & 3.0 & Room temp. & $\begin{array}{l}2 \\
3\end{array}$ & $\begin{array}{l}34 \\
30\end{array}$ \\
\hline Mg II & 2.9 & Liquid air & $\begin{array}{l}1 \\
2 \\
3\end{array}$ & $\begin{array}{l}40 \\
34 \\
30\end{array}$ \\
\hline
\end{tabular}

* Aluminum substrate.

*** First number refers to substrate, second to coating. $Z \mathrm{n} V$ had an aluminum substrate; Cd IV had a copper one.

*** Copper substrate.

bringing them up to room temperature and exposing them to the air. Thus these films could never be studied exactly as they were formed. However, visual observation of the formation of the film was carried out for each evaporation, and some conclusions could be drawn from that.

\section{(A) Aluminum}

Six evaporations of the metal were made, and a total of twenty specimens were available for study. At currents of approximately 8 amperes (filament color, orange) the aluminum fused and flowed throughout the filament coil wetting it well. Good evaporation took place at currents of 13-15 amp. (white hot filament). The metal coated the specimen screens and the inside of the evaporation chamber with a highly reflecting mirror surface.

In the microscope only about a dozen openings at the center of the wire mesh could be studied, and the surfaces of all available squares of a given specimen showed remarkable uniformity. This was to be expected, as the total surface studied 
was less than one square millimeter, and at distances of 30 to $80 \mathrm{~mm}$ from the source this should be quite uniformly covered.

In many cases dust particles and their shadows were included in the photographs as an aid to focusing. It was found necessary to take a series of photographs of each region in order to get a sharp picture.

Figures 2 through 5 show the results of a typical run (AIII) with no cooling of the screens attempted. All show a surface made up of agglomerates with channels between them, and apparently have no material in the channels, as the density of these interstices is the same as the density of the shadows cast by the dust particles. As the amount of material deposited increases. the size of the agglomerates also increases, and they appear to show more angularity. This latter effect may be due to the inability of the microscope to resolve the angles in the thinner speci-

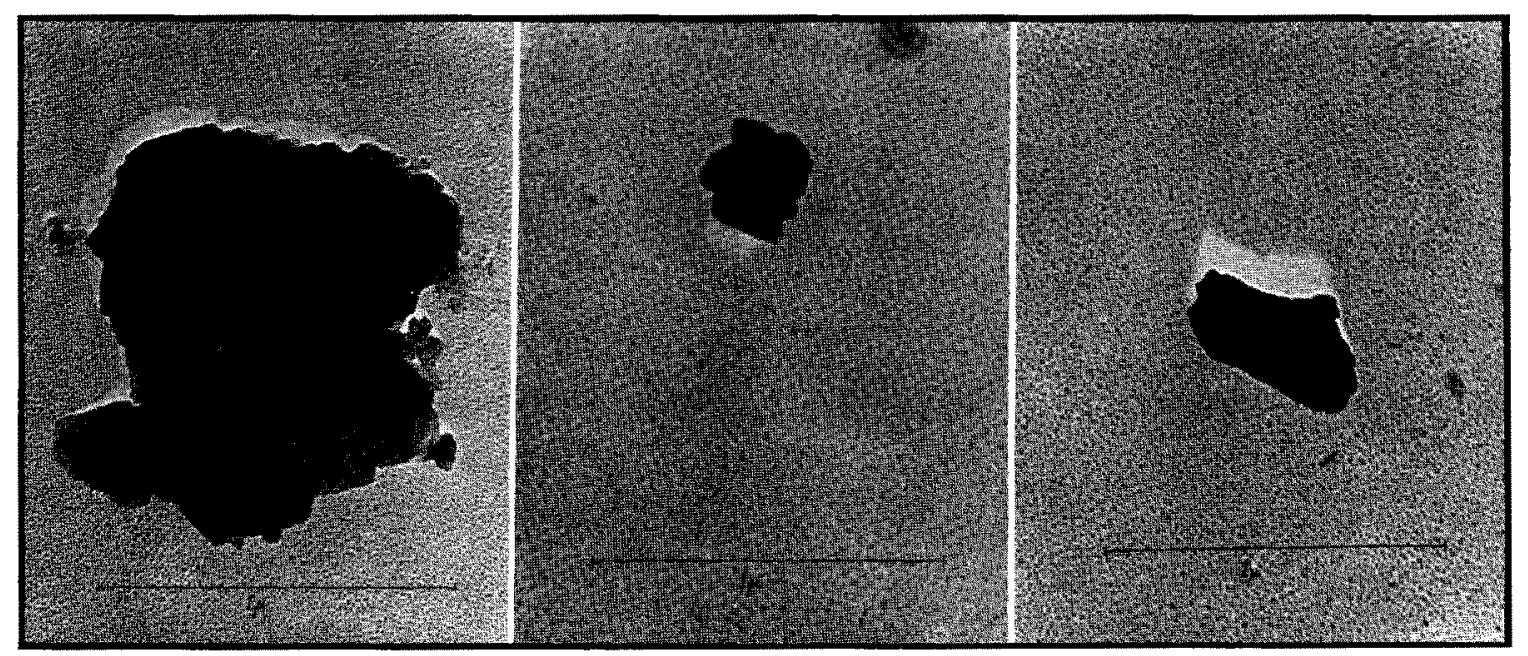

Fic. 2.

FIG. 3.

FIG. 4.

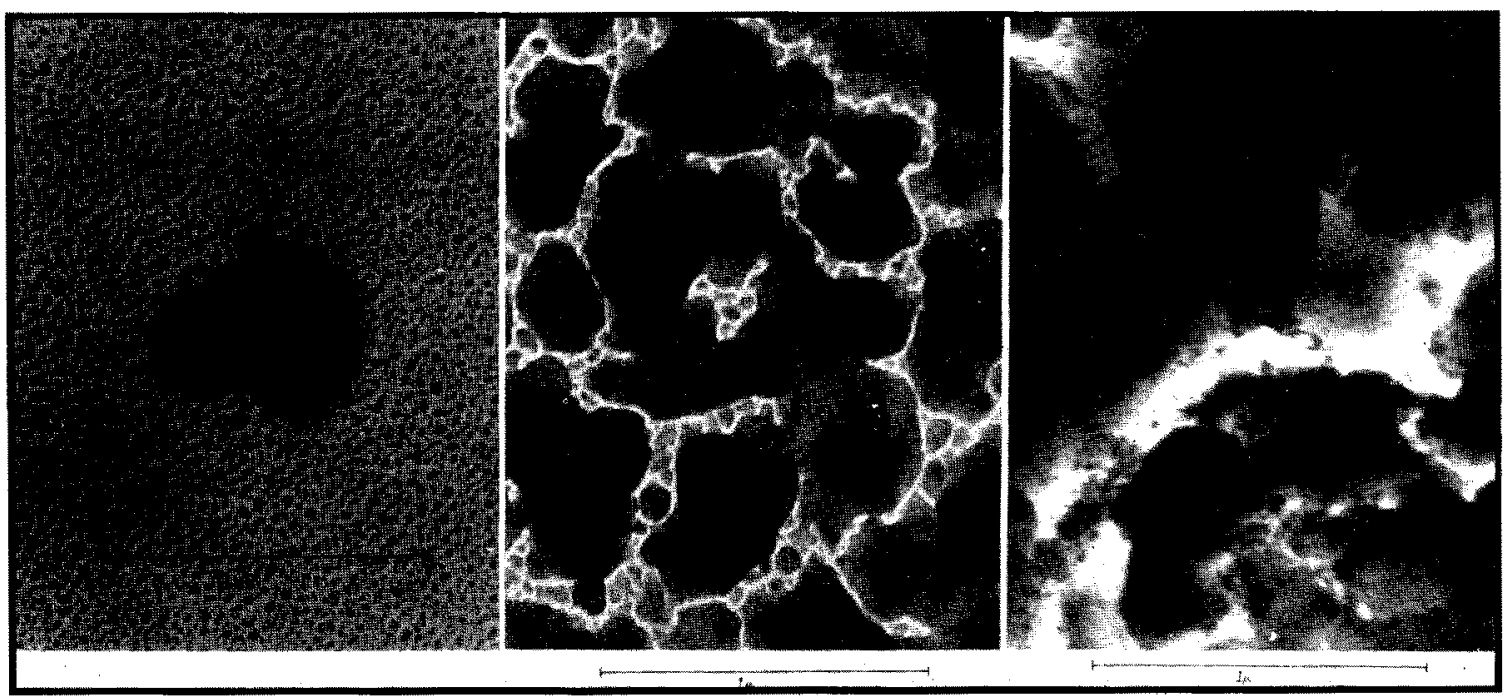

Fici. 5.

FIG, 6.

Fic. 7 .

Fics. 2 7. Alumimm on collodion. The films are successively thicker. Note the shadows cast by the dust particles in Figs. 2, 3, and 4 . 


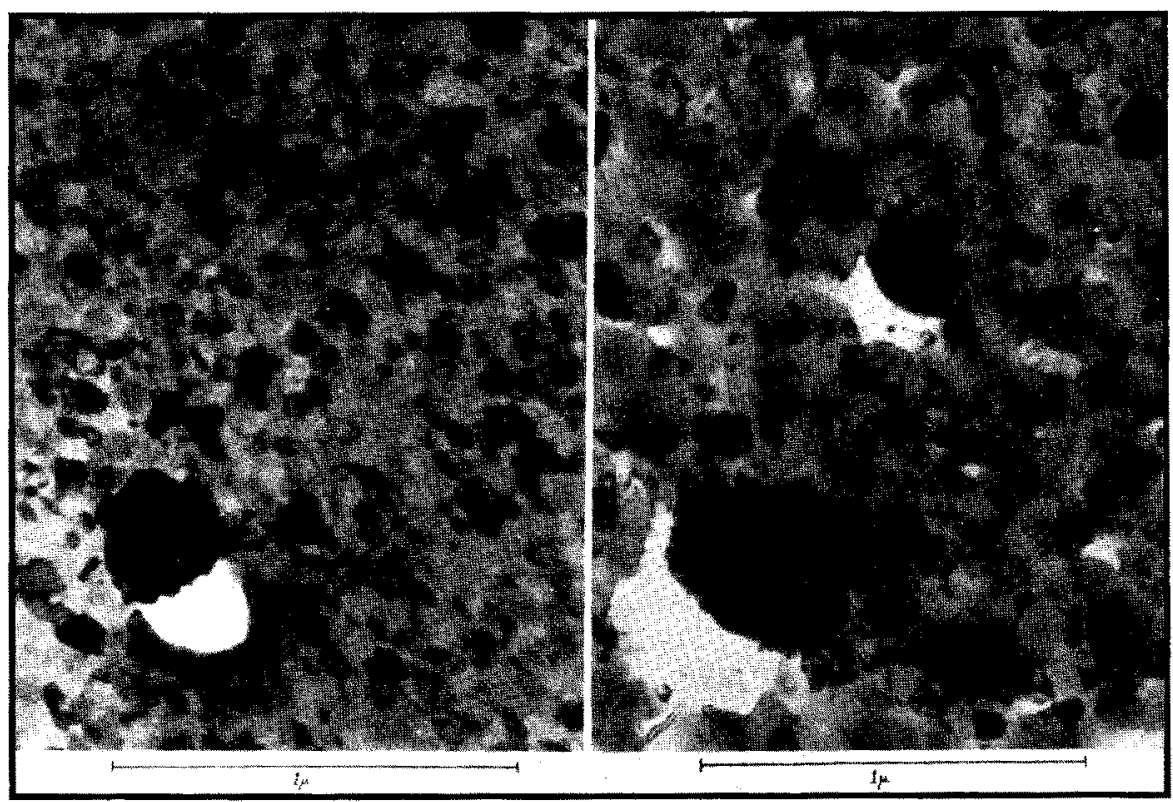

FIG. 8 .

FIG. 9.

Figs. 8 and 9 . Aluminum condensed on liquid-air-cooled collodion substrates. The sharp, dark lines are caused by crystalline reflections.

mens, photographs of which, however, demonstrate a resolving power of 25A. In Figs. 6 and 7 are shown much heavier deposits $(A \mid \mathrm{V})$ prepared under the same conditions. In the former very large agglomerates have built up with smaller ones between, and the interstices are still visible. The heaviest deposit shows quite complete covering of the substrate.

Thin films of aluminum condensed on a liquidair-cooled surface exhibit no new characteristics. Heavier films, however, cover the substrate quite completely and show many sharp, dark lines as seen in Figs. 8 and 9. According to Hillier and Baker ${ }^{5}$ these are produced when strong reflection of the electron beam occurs at a crystal plane appropriately oriented with respect to the beam. Such a reflection prevents a portion of the beam from passing through the limiting aperture; thus no electrons from the corresponding part of the specimen will strike the photographic plate, and a black region will appear in the photographic print. Lines of this sort are evidence of the presence of well developed crystals on the surface.

Visual observation of the aluminum surface on the cooled parts of the evaporating chamber as it

\footnotetext{
J. Hillier and R. F. Baker, Phys. Rev. 61, 722 -3 (1942).
}

rose to room temperature gave no indication of any change in structure. The metal always formed a fine mirror which stuck well to the glass and the collodion.

One fim was photographed six months after it was made, and showed a structure in agreement with that observed for freshly prepared specimens. From this one can conclude that if oxidation takes place it does not change the physical structure of the film, assuming that the fresh films do not react with the atmosphere completely instantly upon contact.

\section{(B) Gold}

In order to check more completely the effect of oxidation of the metals upon the surface structure, gold was used. The metal fused at a current of $15 \mathrm{amp}$. (white hot filament) and evaporated well at that current. Figure 10 shows a typical surface. Its structure is the same as that of an aluminum fim. Thicker deposits showed a complete covering of the substrate and disappearance of the interstices. Extremely thin specimens (too thin to show color) showed a definite granulation of the surface with the size of the agglomerates just below the resolving power of the microscope. 


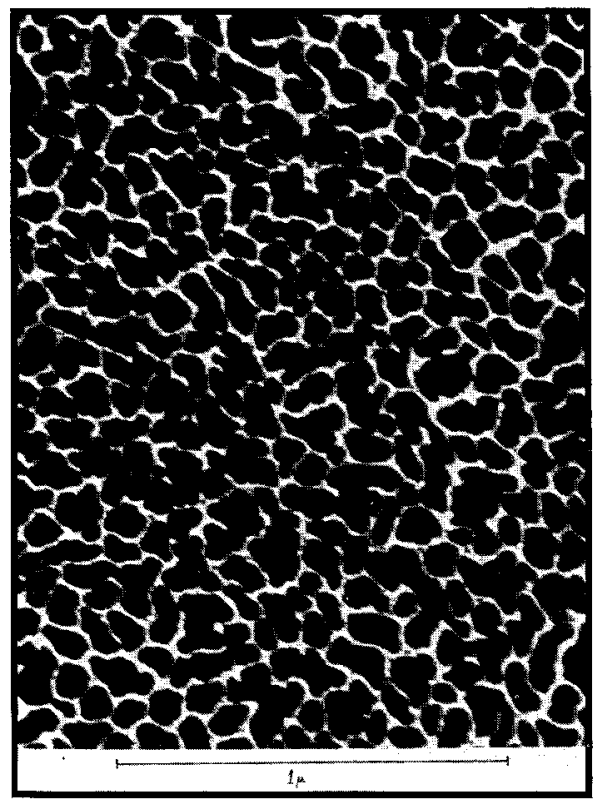

FIG. 10. Gold on collodion.

This agrees with Germer's conclusion from clectron diffraction studies. ${ }^{6}$

\section{(C) Zinc}

Zinc was evaporated at currents of about 2 amp. (filament just starting to show color). In no

${ }^{6}$ L. H. Germer, Phys. Rev. 56, 58-71 (19.39). case did the metal melt and wet the filament as observed by Caldwell, ${ }^{3}$ but it seemed to sublime directly.

The zinc specimens condensed at room temperature showed large blank spaces with occasional crystals of the metal, clusters of crystals, large transparent forms, and irregular particles resembling droplets (Figs. 11 through 13).

The large, transparent structures are undoubtedly big crystals of the metal of such thickness as to be totally opaque to the electron beam. However, in this case density of the electron microscope image is not uniquely determined by the mass thickness of the specimen. ${ }^{5}$ The observed structure is due to electrons which were reflected from the crystal but were brought back by the field of the lens and passed through the limiting aperture to give an image on the photographic plate.

The spaces between particles were considerably greater than the particle size in the few regions where any metal was present at all. The zinc formed a bluish, splotchy surface on the glass, and appeared in parts of the tube far within the shadow of obstacles. This latter effect was especially noticeable in one case when the filament temperature became too high during the evaporation, and it may readily be concluded that the zinc was reflected several times from the

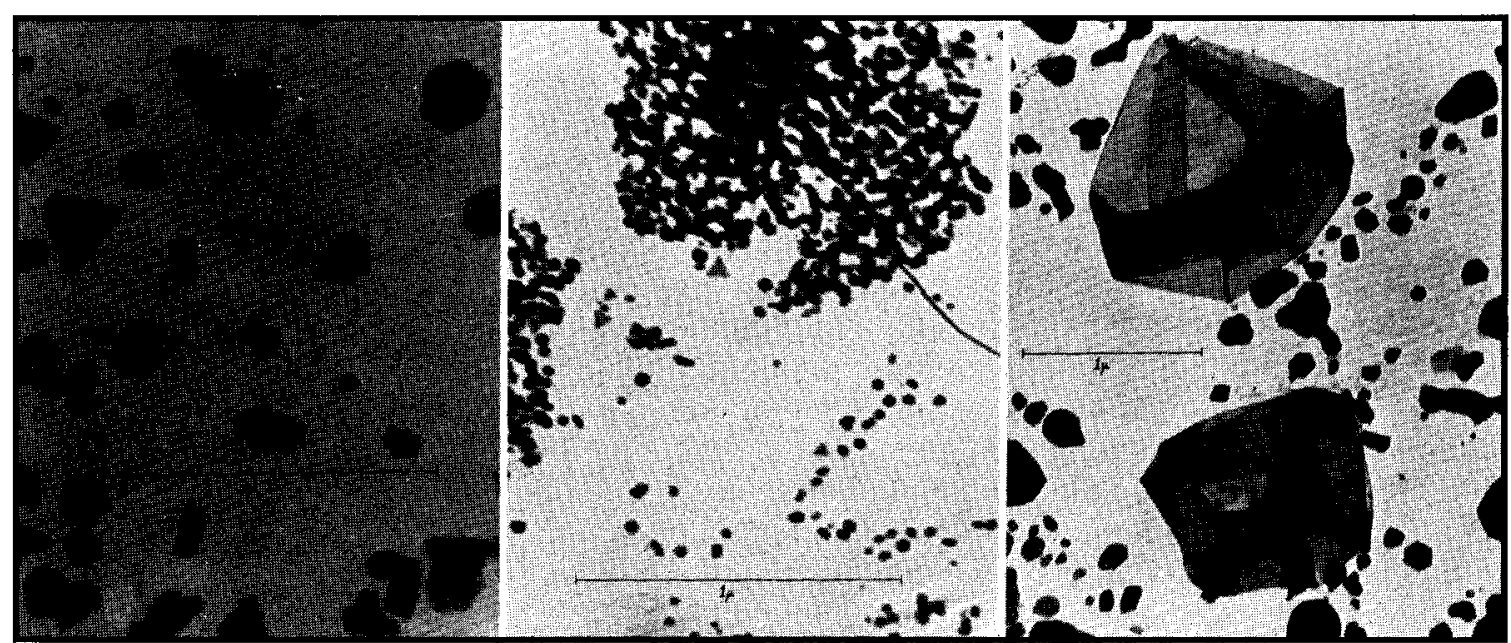

FIG. 11.

FIG. 12.

FIG. 13.

Figs. 11-13. Zinc on collodion. 


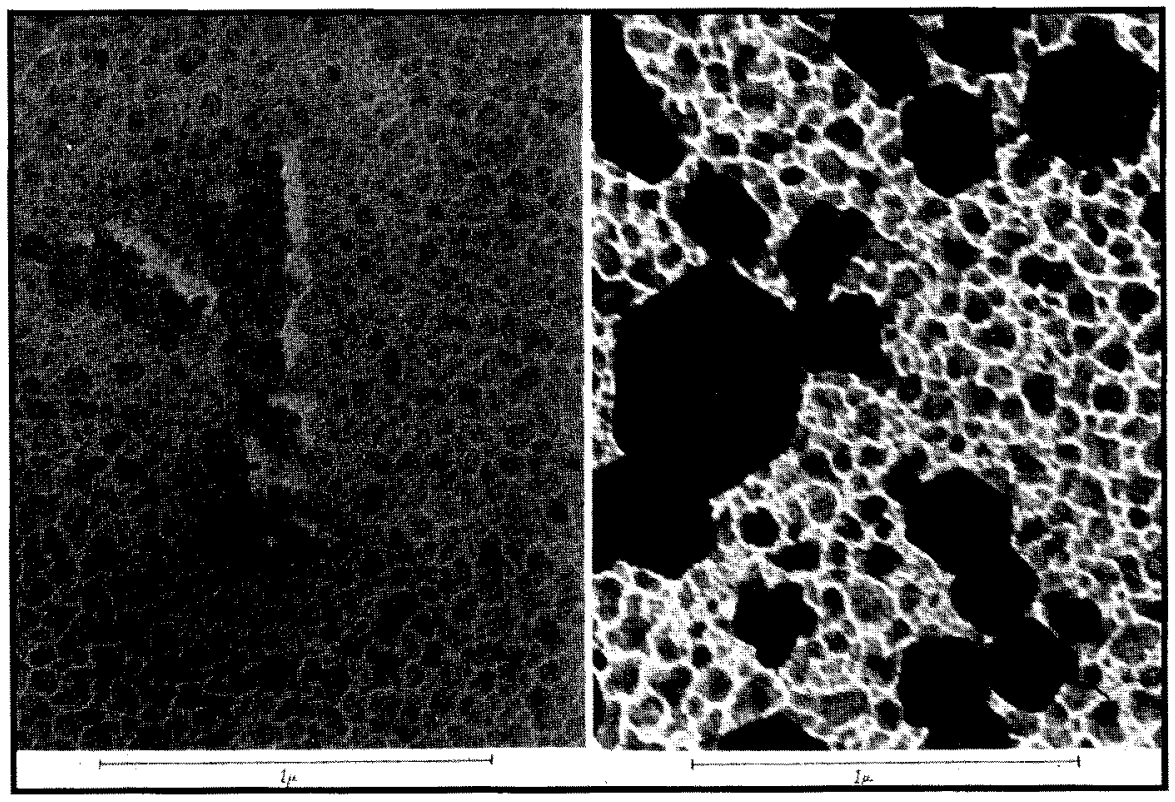

Fici. 14.

FIG. 15.

Figs, 14 and 15. Numinum coverel collodion flm before and after zinc was condensed on it.

walls of the chamber before it finally stuck. The metal could casily be wiped from the glass.

When the condensing surface was cooled with liquid air the zinc formed a fine mirror surface on the cold glass but still did not coat the collodion well. On the uncooled glass surface the usual nonuniform, bluish deposit was observed. When the liquid air was removed from the platform and the glass gradually rose to room temperature, the highly refecting mirror surface of zine disappeared to leave ultimately a semi-transparent bluish coating as on the rest of the glass. Apparently a recrystallization of the metal had taken place below room temperature, and the zinc had gone over to the form of relatively large crystals with considerable space between them. The collodion films again showed no trace of a homogencous surface, but only scattered crystals and droplets.

To check the effect of the substrate on the formation of zinc surfaces, the metal was next condensed at room temperature on one of the aluminum films, and two plain collodion films were included for comparison. These latter were no different in appearance from previous specimens, but the aluminum coated collodion took an excellent covering of zinc. Figures 14 and 15 show the aluminum background before and after the zinc was evaporated. The type of surface formed is shown at lower magnification in Fig. 16. Ex-

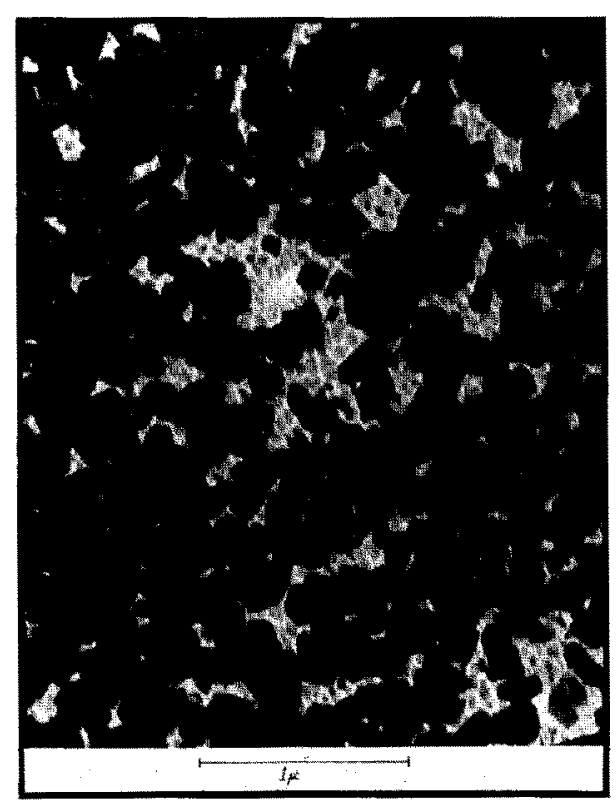

Fig. 16. Tinc on aluninum. 


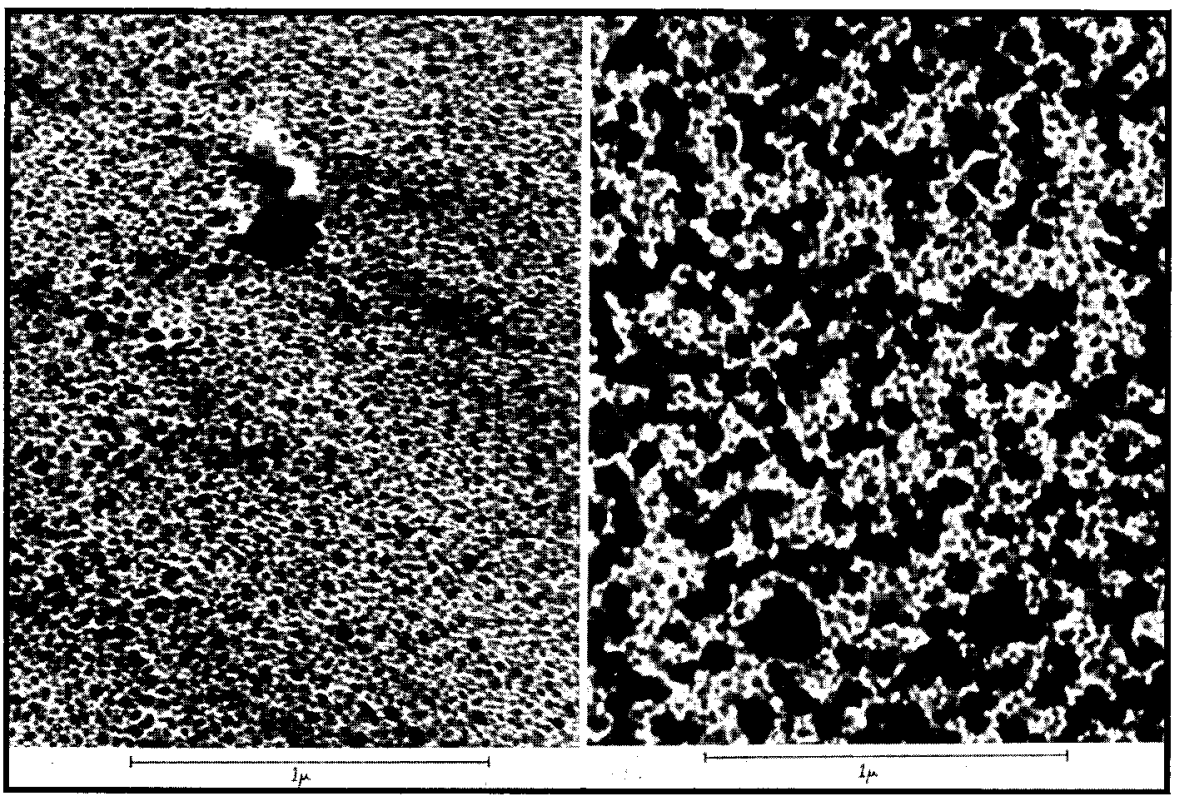

FIG, 17.

Fig. 18.

FIGs. 17 and 18. Copper covered collodion film before and after zinc was condensed on it.

amination shows that the zinc never forms a film of the type observed with aluminum, but a thick network of fairly well developed crystals.

This experiment was repeated with liquid-air cooling of the films. Aluminum was evaporated

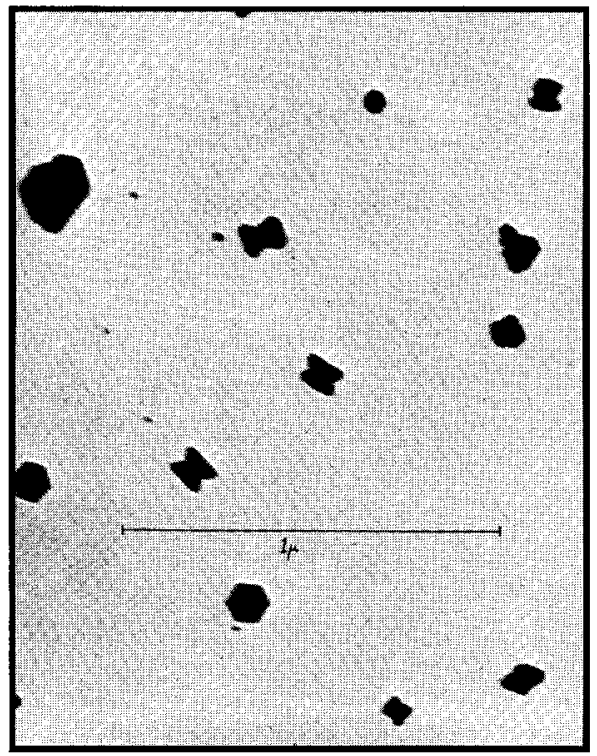

FIG. 19. Cadmium on collodion. from the rear filament and zinc from the front one after the aluminum evaporation was completed $(\mathrm{ZnV})$. The films produced were much the same as those formed at room temperature, and, in addition, many of the large transparent forms appeared on the aluminum surface.

Finally, zinc was evaporated at room temperature onto a previously prepared copper film $(\mathrm{Zn} \mathrm{VI})$. Figures 17 and 18 show this specimen before and after the zinc was evaporated. Again the network of zinc crystals was formed.

\section{(D) Cadmium}

Cadmium was evaporated at currents of $1 \mathrm{amp}$. or less. The metal formed a bluish, non-uniform surface on the glass as zinc did, and did not coat the collodion well. Electron microscopic examination of the specimens showed irregular patches of the metal and, frequently, regions of well formed crystals, but a general coating was never obtained.

When the metal was condensed on a liquid-aircooled surface it formed a fine mirror on the cold platform tube and the usual spotty surface on the uncooled glass. The collodion did not take a good coating. Upon being warmed to room temperature 


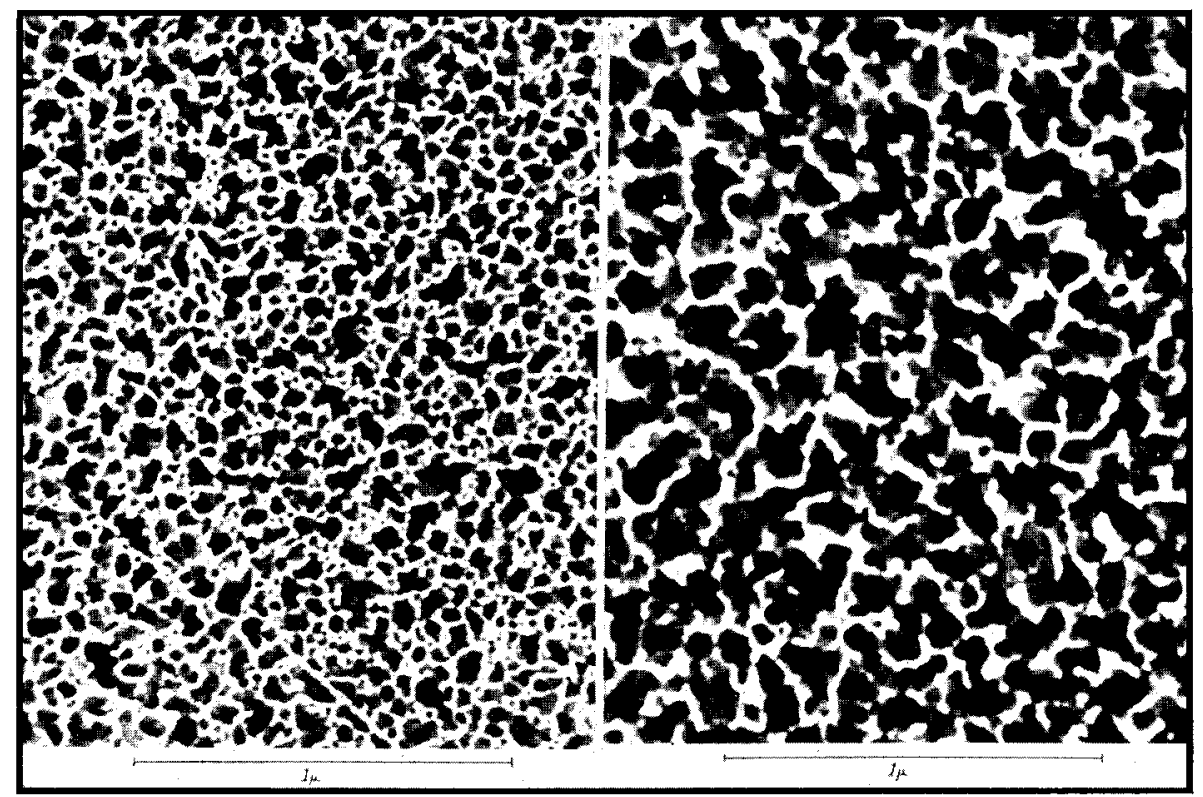

Fig, 20.

FIG, 21.

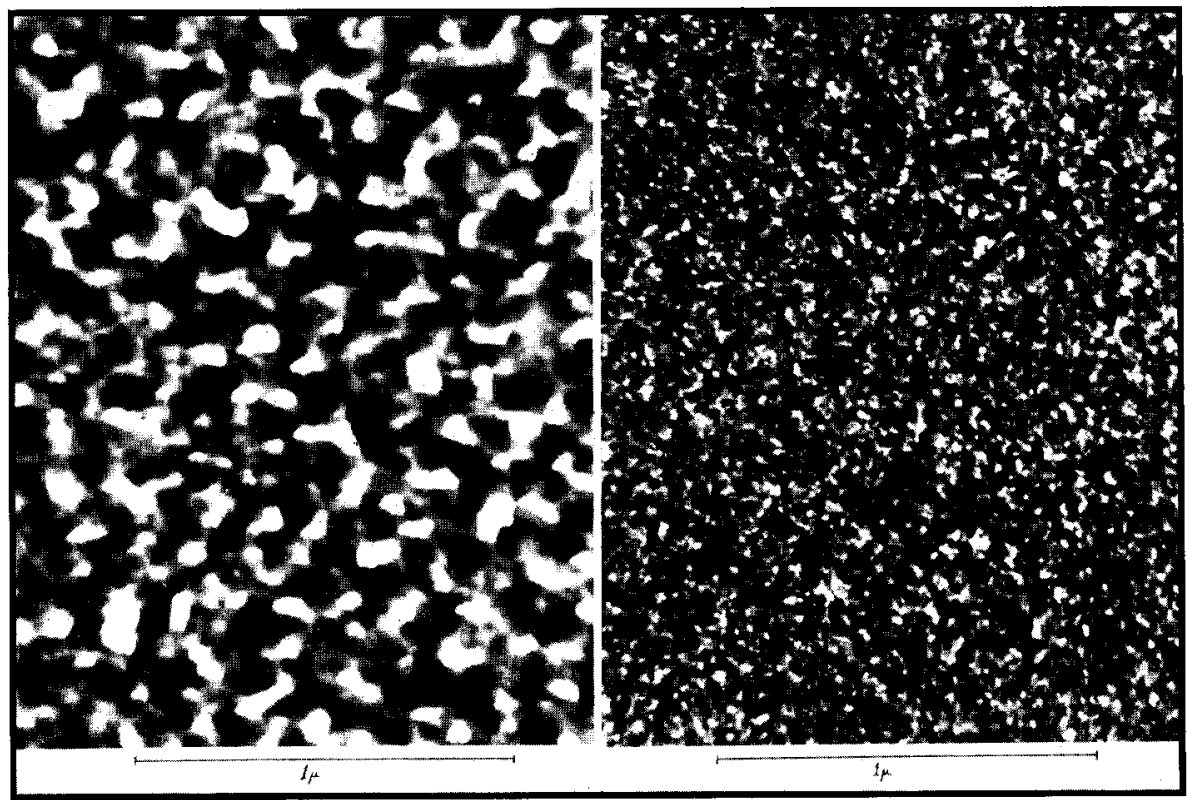

FIG. 22.

FIG. 23

FIGs. 20-23. Copper on collodion. The films are successively thicker.

after removal of the liquid air, the mirror surface did not disappear. The collodion films again showed numerous irregular patches of the metal and many well-defined crystals. Many of these crystals appear to be twinned (Fig. 19).
Finally, cadmium was condensed on a previously prepared copper surface. It coated the substrate very well, but again in the form of small crystals as the zinc had done. One specimen very heavily covered with cadmium when put in the 


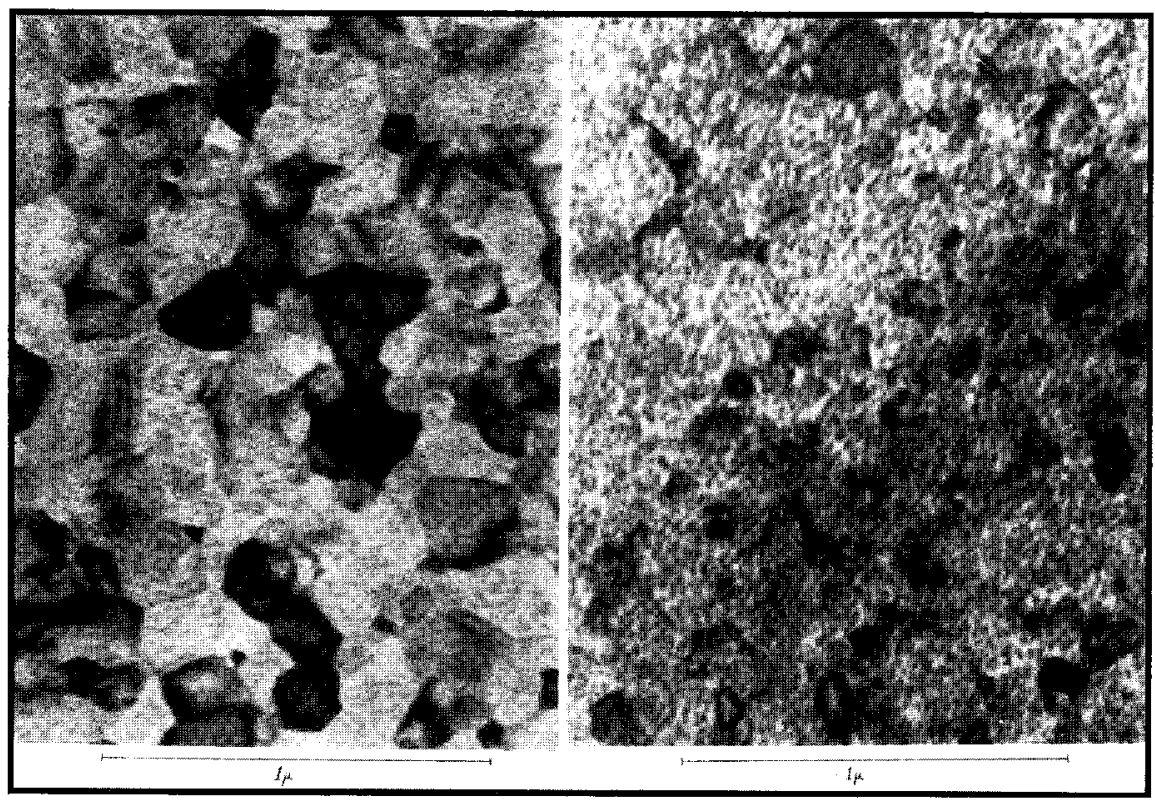

FIG. 24.

FIG. 25.

Figs. 24 and 25. Magnesium on collodion.

microscope seemed to undergo a redispersion of the cadmium, as it apparently disappeared in the beam. This was the only case for any film in which the beam was seen to affect the specimen.

\section{(E) Copper}

The metal fused and wet the filament well; good evaporation was obtained with a white hot filament. The copper coated the collodion films evenly, forming surfaces much like aluminum and producing a mirror on the glass. At liquid-air temperatures the same type surfaces were formed showing agglomerates with channels between them, and the gradual disappearance of the interstices as the deposit grew heavicr. Results of a typical run (Cu II) are shown in Figs. 20 through 23.

\section{(F) Magnesium}

The metal did not wet the filament but sublimed at currents of three to five amperes (filament color, bright red), forming a mirror surface on the glass and coating the collodion films uniformly. Electron microscopic examination of films produced at room temperature showed a background of very small agglomerates overlaid with larger crystals (Figs. 24 and 25). Films condensed at liquid-air temperature showed a similar structure, with the size of the agglomerates increasing with thickness of deposit.

\section{CONCLUSIONS}

The knowledge of the structure of thin metallic films can be increased by the application to the problem of a new tool, the electron microscope. While only surfaces on substrates transparent to electrons can be studied, they show certain general features that may be easily recognized. All the surfaces studied appear to be made of aggregates of the metal separated by interstices of various widths, and the extremely high resolving power of the electron microscope enables accurate measurements of the grain and channel sizes to be made, whereas previously these could be only inferred and estimated.

For determination of the crystalline structure of those metals that form homogeneous surfaces, electron diffraction studies seem to offer more information than the electron microscope can. The pictures of the granules in many cases show only irregularly shaped aggregates which may be amorphous or crystalline, as they are large 
enough to include many unit cells. Electron diffraction investigations seem to indicate that the crystalline structure is the more common form.

Electron diffraction studies also seem to offer more than the electron microscope in determining the degree of oxidation of the specimens. Microscopic observation shows no apparent change in surface structure of films known to be considerably oxidized, although it is possible that extended studies of a readily oxidizable film might show changes in grain size and channel widths as the chemical reaction proceeded.

The observed surface structure and the fact that very sharp shadows of obstacles in the evaporating chamber were formed when aluminum, magnesium, gold, and copper were evaporated can be explained on the assumption that the metals are given off from the filament in the form of molecular rays, and whatever structure is observed in the final film is due to the slight migration (not over 500A) of the atoms of these metals over the substrate after condensation. This migration of atoms over a surface has been well established by other means of investigation, and the electron microscope studies offer strong supporting evidence for it.

The non-uniform surface of zinc and cadmium on glass at room temperature and the appearance of these metals in the shadow of obstacles in the evaporating chamber show that the atoms are reflected from glass surfaces, losing some of their energy upon each impact until their energy is less than the latent heat of evaporation of the metal from glass. They then migrate over the surface until the stable crystalline forms are developed, leaving large areas of blank substrate between particles as pictured in Figs. 11 through 13. The surface structure as photographed is in excellent agreement with theories developed from such indirect methods of investigation as conductivity and optical reflectivity studies.

The electron microscope studies can be used to go a step further than the above indirect methods in explaining the formation of mirror surfaces. Measurements of the widths of the interstices between granules of such metals as aluminum, magnesium, copper, and gold, which form homogeneous surfaces, show that they are of the order of 100 to $500 \mathrm{~A}$, while the grains of the metal are much larger. Since the channel width is a small fraction of the wave-length of visible light, any light waves striking the metallic surface will be reflected as if the surface were continuous. On the other hand, surfaces of such metals as zinc and cadmium formed at room temperature have spaces between particles much greater than the particle size and of the order of magnitude of the wave-length of visible light, so that these surfaces will have a higher transmission coefficient for light and a lower reflection coefficient. The fine mirror surfaces observed for zinc and cadmium on glass at liquid-air temperature may be explained on the assumption that these metals at low temperatures form surfaces of much the same type as aluminum does, and as the temperature rises the kinetic energy and thus the mobility of the atoms increases until the relatively large crystals are formed with considerable space between them, resulting in the drop in the reflection coefficient. The surfaces as formed on liquid-aircooled substrates could not be studied in the microscope prior to any crystallization occurring between $-183^{\circ} \mathrm{C}$ and room temperature.

This explanation of the surface formation is in agreement with the theory developed by Lennard-Jones. ${ }^{9}$ According to this theory, an atom on a surface is held there by a field of force which has a certain potential at every point. The surface has pockets of low potential separated by potential barriers, and at very low temperatures any deposited atoms will vibrate about the minima of these potential wells, as the energy of the atoms depends directly on the temperature. The latent heat of evaporation of the atom from the surface, $L_{s}$, will be the average energy required to remove an atom completely from the influence of the surface, assuming the atom is initially in its lowest vibrational level. But in order to move freely over the surface an atom needs much less kinetic energy than $L_{s}$. If the atom is given sufficient kinetic energy, $A$, for it to surmount the highest potential barrier along the surface, it may move freely over the entire surface as long as it retains this energy. Since $A$ is less than $L_{s}$, free motion of the atoms on the surface is possible at temperatures below those needed to evaporate the atoms from the surface.

J J. E. Lennard-Jones, Trans. Faraday Soc. 28, 333-359 (1932). 
Both $A$ and $L_{8}$ depend on the nature of the surface and the atom concerned.

On the basis of the above theory Appleyard classifies metallic films into three broad classes depending on the stability of their first layers. For type I surfaces, $L_{s}>L_{m}$, where $L_{m}$ is the latent heat of evaporation of the metal from itself, and the first layer is inherently stable. For type II, $L_{s}<L_{m}$, but $L_{s}$ is 1 electron-volt or more, and $A$ is a few tenths of an electron-volt. For this type fairly coherent films may be formed at temperatures below $-183^{\circ} \mathrm{C}$, but as the temperature rises agglomeration takes place due to the increased energy and hence increased mobility of the atoms. For type III, $L_{s}<L_{m}, L_{s}$ is about 0.1 electron-volt, and $A$ is only a few hundredths of an electron-volt. Such films show rapid agglomeration even at extremely low temperatures of deposition, as $A$ (which measures the maximum height of the potential barriers) is so small.

The change in optical reflectivity and the observed physical reflection of their atoms from the substrates lead to the conclusion that the potential wells for zinc and cadmium on the substrates studied are much shallower than for aluminum, copper, gold, and magnesium, and deeper for cadmium than for zinc, as the former metal did not undergo as great a loss in reflectivity as the zinc did when the glass rose to room temperature.

The potential barrier for migration of zinc and

TABLE III. Classification of surfaces studied according to Appleyard's scheme.

\begin{tabular}{clc}
\hline \hline \multicolumn{1}{c}{ Metal } & Substrate & Class \\
\hline Aluminum & Collodion & II \\
Glass & I I \\
Cadmium & Collodion & III \\
& Glass & III \\
Copper & Copper & II \\
& Glass & II \\
Gold & Collodion & II \\
& Glass & II \\
Magnesium & Collodion & II \\
& Glass & II \\
Zinc & Collodion & III \\
& Glass & II \\
& Copper & II \\
\hline
\end{tabular}

cadmium on collodion is apparently less than for these metals on glass, as they did not form observable mirror surfaces on the collodion film even at liquid-air temperature. However, it must be remembered that the collodion films were probably not at as low a temperature as the glass when liquid air was used, even though the filament was giving off very little heat during the evaporation of these metals, and the added kinetic energy received by the metal atoms from the substrate might have been enough to allow them to surmount the potential barrier of a collodion surface even if it were as high as that for a glass surface. Furthermore, the relative cleanliness of the two substrates cannot be determined, and this is known to influence the height of the potential barrier for migration. ${ }^{1}$

When zinc or cadmium was evaporated onto substrates of copper or aluminum, a much more nearly complete covering of the surface was observed than in previous cases. From this it may be inferred that the adhesive forces and thus the latent heats of evaporation for these metals on copper and aluminum substrates are much greater than the forces that exist between these metals and glass or collodion. However, the formation of well-developed crystals with relatively large distances between them (Figs. 15 and 18) shows that there is considerable migration of the atoms and leads to the conclusion that the kinetic energy required for migration is still quite low. This conclusion holds for unoxidized aluminum and copper surfaces also, as in two cases the zinc and cadmium were evaporated onto freshly formed aluminum and copper substrates that had not been exposed to the air and again formed crystals of the type described.

In Table III the metals studied in this investigation are listed in accordance with Appleyard's classification as given above. None of the electron microscope studies gave evidence of the formation of an inherently stable first layer of metal giving rise to a continuous film, so none of the metals formed type I surfaces on the substrates used. The classification in this table is fundamental in that it is based on the actual distribution of potential over the surface. This is known for very few metals and substrates, but electron microscopic investigation offers a new and simple method of determining the type of surface and 
the order of magnitude of the potential barriers, although it does not give an absolute value for the minimum kinetic energy required for migration.

An additional classification is suggested which may prove useful in further electron microscopic investigations of thin films. This is based on the observed mobility of the atoms at various temperatures. Such a criterion is useful in that it gives an indication of the relative heights of the potential barriers and the adhesive forces between the films and substrate.

Class A-Surfaces which recrystallize with increasing temperature to form agglomerates separated by interstices which are much narrower than the diameter of the aggregates.

Class B-Surfaces which recrystallize with increasing temperature to form agglomerates separated by interstices of the same order of magnitude as the diameter of the particles.

Class C-Surfaces which recrystallize with increasing temperature to form relatively isolated crystals.

The surfaces studied are listed with their appropriate classes in Table IV.

Comparison of this classification with Appleyard's shows that both classes A and B are included in his type II group, and class $C$ is identical with his type III. Appleyard's type I surfaces are not amenable to electron microscope investigation, as the instrument in incapable of resolving the structure of the uniform films included in this group. Electron diffraction studies should give more information regarding the structure of such films.

Electron microscope photographs of the thickest metallic films that could be penetrated (Figs. 7, 16, and 23) show that these surfaces are very porous. The interstices largely disappear under successive layers of metal, but at no time is a thoroughly uniform film formed. These
Table IV. Classification of surfaces studied on the basis of the electron microscopically observable particle size to interstitial distance ratio.

\begin{tabular}{|c|c|c|}
\hline Metal & Substrate & Class \\
\hline Aluminum & $\begin{array}{l}\text { Collodion } \\
\text { Glass }\end{array}$ & $\begin{array}{l}A \\
A\end{array}$ \\
\hline Cadmium & $\begin{array}{l}\text { Collodion } \\
\text { Glass } \\
\text { Copper }\end{array}$ & $\begin{array}{l}\mathrm{C} \\
\mathrm{C} \\
\mathrm{B}\end{array}$ \\
\hline Copper & $\begin{array}{l}\text { Collodion } \\
\text { Glass }\end{array}$ & $\begin{array}{l}A \\
A\end{array}$ \\
\hline Gold & $\begin{array}{l}\text { Collodion } \\
\text { Glass }\end{array}$ & $\begin{array}{l}\mathrm{A} \\
\mathrm{A}\end{array}$ \\
\hline Magnesium & $\begin{array}{l}\text { Collodion } \\
\text { Glass }\end{array}$ & $\begin{array}{l}\mathrm{A} \\
\mathrm{A}\end{array}$ \\
\hline Zinc & $\begin{array}{l}\text { Collodion } \\
\text { Glass } \\
\text { Aluminum } \\
\text { Copper }\end{array}$ & $\begin{array}{l}\mathrm{C} \\
\mathrm{C} \\
\mathrm{B} \\
\mathrm{B}\end{array}$ \\
\hline
\end{tabular}

pictures and those of thinner films offer new and conclusive evidence as to why surfaces deposited by condensation from the vapor have such high adsorptivity and absorptivity.

\section{SUMMARY}

In conclusion it may be said that the electron microscope studies of the structure of thin films by providing actual pictures of the surfaces give strong evidence in support of the theory of migration of atoms over substrates, provide a simple means of classifying such surfaces with respect to the surface energies of the atoms, explain the optical reflectivity and anomalous conductivity of the films, and establish their porosity, thereby doing much to explain the adsorptivity of these surfaces.

The authors wish to express their appreciation to Professor L. Thomassen of the University of Michigan for valuable advice given during the course of this investigation, and to the Rackham Fund for a grant-in-aid which made possible the carrying out of this investigation. 